\title{
BMJ Open Knowledge, behaviour and attitudes towards Chagas disease among the Bolivian migrant population living in Japan: a cross-sectional study
}

Inés María Iglesias Rodríguez, ${ }^{1}$ Shusaku Mizukami, ${ }^{2}$ Dao Huy Manh, ${ }^{2}$ Tieu Minh Thuan, ${ }^{3}$ Hugo Alberto Justiniano, ${ }^{4}$ Sachio Miura, ${ }^{5}$ George Ito, ${ }^{6}$ Nguyen Tien Huy, ${ }^{7,8}$ Chris Smith, ${ }^{8}$ Kenji Hirayama (D) ${ }^{2}$

To cite: Iglesias Rodríguez IM, Mizukami S, Manh DH, et al. Knowledge, behaviour and attitudes towards Chagas disease among the Bolivian migrant population living in Japan: a crosssectional study. BMJ Open 2020;10:e032546. doi:10.1136/ bmjopen-2019-032546

- Prepublication history and additional material for this paper are available online. To view these files, please visit the journal online (http://dx.doi. org/10.1136/bmjopen-2019032546).

Received 24 June 2019 Revised 26 May 2020 Accepted 27 May 2020

Check for updates

(C) Author(s) (or their employer(s)) 2020. Re-use permitted under CC BY-NC. No commercial re-use. See rights and permissions. Published by BMJ.

For numbered affiliations see end of article.

Correspondence to Dr Kenji Hirayama; hiraken@nagasaki-u.ac.jp and Dr Nguyen Tien Huy; tienhuy@nagasaki-u.ac.jp

\section{ABSTRACT}

Objectives This study aimed to investigate the knowledge, behaviour and attitudes towards Chagas disease (CD) among Latin American migrants in Japan and to evaluate the effectiveness of an educational activity (EA) in increasing knowledge of $\mathrm{CD}$.

Design A cross-sectional, mixed-methods study employing a preknowledge and postknowledge test and focus group discussion, conducted from March 2018 to June 2018.

Participants Seventy-two participants were included, all born in Bolivia and residents in four Japanese cities. Fiftynine of them participated in the EA.

Interventions The EA comprised showing three videos about $C D$ and a group discussion covering different dimensions of $C D$ and was evaluated with questionnaires to analyse the knowledge of the participants before and after.

Results Seventy-two participants were enrolled, predominantly from highly endemic CD areas of Bolivia. Though most participants were familiar with vector-borne transmission, epidemiology and symptomatology of CD, the baseline knowledge of CD was low. Less than $10 \%$ of them had been tested prior for $\mathrm{CD}$. The dominant factors associated with better knowledge were living in Japan for more than 10 years $(\mathrm{OR}=8.42,95 \% \mathrm{Cl} 1.56$ to 48.62$)$ and previously testing for $\mathrm{CD}(\mathrm{OR}=11.32 ; 95 \% \mathrm{Cl} 1.52$ to 105.9). The EA significantly improved the $C D$ knowledge of the participants (p value $<0.0001 ; 95 \% \mathrm{Cl} 2.32$ to 3.84 ). The participants associated the term 'Chagas' mostly with fear and concern. The level of stigmatisation was low, in contrast to the results of other studies. The barriers encountered in care-seeking behaviour were language, the migration process and difficulties to access the healthcare system.

Conclusion EA with an integrative approach is useful to increase the knowledge of CD within the Bolivian migrant population living in Japan. The activity brings the possibility to explore not only the level of knowledge but also to reveal experiences and to understand the needs of the people at risk. Considering them as actors towards healthcare solutions could lead to better outcomes for the success of future policies and interventions aimed to decrease the global burden.
Strengths and limitations of this study

- Most of the participants were not previously tested for Chagas disease, thus providing a snapshot of the knowledge, conceptions and representations of the disease which were not strongly biased or impacted by previous contact with the healthcare system.

- The questionnaires used in this study were mostly based on previous studies and were not independently evaluated.

- The study does not measure the sustained effect of the educational activity on knowledge over the time.

\section{INTRODUCTION}

It has been more than 100 years since the discovery of Chagas disease (CD) and although the estimated number of infected people has fallen, almost $6-7$ million people are affected worldwide. ${ }^{1-3}$ Just $1 \%$ of the affected people can access diagnosis and treatment. ${ }^{4}$ Each year, 39000 new cases occur, of which 9000 result from congenital transmission. ${ }^{1}$ In Latin America (LA), CD is one of the tropical diseases with the highest burden, measured as over 800000 disability-adjusted life-years. The economic impact is about 685 million dollars annually in health expenditure worldwide. ${ }^{5}$

Bolivia is the country with the highest prevalence of $\mathrm{CD}$ worldwide $(6.1 \%){ }^{1}$ It has the highest incidence rate of vectorial transmission $(0,0810$ per 100 habitants over 1 year $)$ and accounts for $92.6 \%$ of all new cases in the Southern Cone Subregion. ${ }^{1}$ During the last few decades, political, economic and social factors accounted for a major migration of Bolivians into urban areas as well as overseas. This urbanisation plays an important role in the change in the paradigm of $\mathrm{CD} .{ }^{6}$

Nowadays, the disease silently persists among population of migrants living in the 
USA, Europe and Western Pacific region. ${ }^{7}$ Japan with nearly 300000 migrants from LA countries is one of the leading countries for migration from LA. ${ }^{8}$ Brazilian $(74 \%)$, Peruvian $(18 \%)$ and Bolivian $(2 \%)$ populations represent the majority of the Latin American migrants living in Japan. ${ }^{5}$ In Japan, there are estimated 3000 cases of $\mathrm{CD}^{7}$ Blood transfusion control is the only measure implemented to limit CD in Japan. ${ }^{9}$ There is an important gap in epidemiological data, with most of the affected population undiagnosed. ${ }^{10}$

CD detection is difficult in non-endemic countries because it is an emerging disease, and health personnel's lack awareness of its silent course. Moreover, the migrant population is confronted with multiple barriers to access the healthcare system. The migrant population is disadvantaged compared with the native citizens of the host country; specifically, the process of careseeking behaviour can be impeded by language, lack of adaptability of the healthcare system and prioritisation of their migratory goals. Currently, less than $10 \%$ of the people affected by $\mathrm{CD}$ are diagnosed in non-endemic countries. ${ }^{2411}$ Studies suggest that lack of knowledge of the people at risk strongly influences their care-seeking behaviour. $^{12-16}$

It is important that the population at risk of contracting $\mathrm{CD}$ has the necessary knowledge to combat it through their daily activities. However, to have better outcomes in knowledge improvement, it is necessary to incorporate underlying population beliefs and conceptions with scientific knowledge. ${ }^{12}$ The conceptions of those affected are the result of their history, environment, cultural context, reality and interactions between these elements. The emergence and persistence of $\mathrm{CD}$ are associated with sociocultural factors, ${ }^{13}$ and thus understanding the prior conceptions of a target group should become the starting point of any educational projects. ${ }^{14}$

Educational activities (EAs) to improve disease knowledge should involve an integrative approach and consider the affected people as main actors where all dimensions of $\mathrm{CD}$ are incorporated. Involving the experience of people affected can be an important tool for developing programmes with better outcomes. One example of an integrative approach where $\mathrm{CD}$ is considered in epidemiological, biomedical, political and sociocultural aspects is an activity presented by the group Consejo Nacional de Investigaciones Científicas y Técnicas (CONICET) 'Hablamos de Chagas' (Let's talk about Chagas). ${ }^{17}$ To our knowledge, there is no other study that analyses the improvement in knowledge of $\mathrm{CD}$ after these EAs.

The primary objectives of our study are to reveal current knowledge and attitudes towards CD in the LA migrant population living in Japan, to analyse the factors associated with better knowledge and to evaluate the effectiveness of an EA in increasing the knowledge of CD. The secondary objective is to identify possible strategies to overcome the existing barriers for the migrant population to access care.

\section{METHODS}

\section{Study design}

This cross-sectional study involved both quantitative and qualitative methods and was conducted following the Strengthening the Reporting of Observational Studies in Epidemiology guidelines as presented in the online supplementary table S1.

The quantitative part was based on two questionnaires administered pre (first questionnaire) and post (second questionnaire) an EA where $\mathrm{CD}$ was covered in an integrative approach.

More than half of the questions were based on two studies, one conducted in the USA to assess the awareness among the LA migrant population living in Los Angeles ${ }^{15}$ and the other in Geneva, Switzerland. ${ }^{18}$

The qualitative part was conducted in the format of four focus group discussions (FGDs). It was included in an EA based on a workshop proposed in the book 'Hablamos de Chagas' by the CONICET group 'Taller I: Construcción colectiva del caleidoscopio' (Collective kaleidoscope construction). The EA considers CD from an integrative approach where the superposition of different experiences and skills creates a complex and complete image about CD. In this activity, the intervention of a moderator is minimum, and the participants serve as the main actors.

We modified the video originally proposed by the CONICET group and replaced the video, 'CHAGAS. Reconocer miradas, sumar voces, acortar distancias' ('CHAGAS. Recognize looks, add voices, shorten distances'), with three videos of Juana and Mateo. ${ }^{19}$ The videos were 'Salud y Enfermedad' (health and disease), 'Embarazo' (pregnancy) and 'Ciudad' (city), chosen to adapt the information to the necessities of the migrant population living in a non-endemic country. These videos illustrate a case of $\mathrm{CD}$ in an urban context, a case of congenital transmission of $\mathrm{CD}$ and an interview with a medical doctor. The content of the videos is related to the indeterminate form; the organs affected in the symptomatic patients and the transmission routes: mother-to-child, blood transfusion and vectorial. The videos also describe the importance of screening in pregnant women and the efficacy of treatment in children.

\section{Variables (quantitative part)}

The first questionnaire (Q1) contained 33 questions, 10 of which relate to knowledge of the disease, including CD demographic information, risk factors and the risk of transmission, also included were questions related to the level of vigilance and policies for $\mathrm{CD}$ in their previous resident areas. Questions regarding barriers to access the healthcare system in Japan and stigmatisation were also included.

The second questionnaire $(\mathrm{Q} 2)$ included only the questions related to knowledge in Q1.

\section{Study areas and study population}

The study was held from March to June of 2018 in private rooms of multipurpose buildings in four cities in central 
Japan: Oizumi (Gunma prefecture), Hadano (Kanagawa prefecture), Nagoya (Aichi prefecture) and Suzuka (Mie prefecture). The cities were selected for their large LA migrant population. The locations and dates were arranged according to the planned itinerant consulate of the Bolivian embassy. We sought 100 participants. Inclusion criteria were LA migrant adult population (18 years old or more) who were residing in Japan.

\section{Recruitment method}

The research team and the Bolivian embassy worked with community leaders to recruit the participants. The activity was also informed by radio, magazine and social network media directed to the Latin American migrant population living in Japan. During the day of the activity, the people who came to the itinerant consulate of the Bolivian embassy for other issues also were invited to participate.

\section{Data collection}

After signing the written informed consent and enrolment, the Q1 was administered to the participant. The EA was then conducted with a total duration of approximately 1 hour. Immediately following the EA, the Q2 was administered for the participants. All communication with the participants was conducted in Spanish by a medical doctor from Spain.

The EA started with the FGD. The discussion started with the question 'What is the first thing that came to your mind when you hear the word "Chagas"?'. The participants wrote their answer on a piece of paper, which would be pasted in a mural divided into the four dimensions of CD: biomedical, epidemiological, political and sociocultural. The videos were then projected and a recap of ideas from the videos was conducted. ${ }^{19}$ The goal of the EA was to construct a kaleidoscopic image of the multidimensionality of CD. The activity finalised with a discussion about barriers that the migrant population found in Japan and their suggestions to overcome these problems.

\section{Data analysis}

The total questionnaire score was 14.5 (online supplementary table S2). To analyse the quantitative data, crosstabulation was conducted with Stata V.2015 for questions not related to knowledge. For questions related to knowledge, we calculated the total points and divided into two groups (high knowledge and low knowledge) using a Bloom's cut-off point of $60 \%$ (corresponding to a score of 8.7) ${ }^{20-22}$ To analyse the knowledge of the participants, we used R Core Team (2018) R. Univariable analysis by Chi-test or Fisher-exact test was conducted to identify factors associated with higher knowledge. ${ }^{23}$ The factors with $\mathrm{p}$ values less than 0.2 were included in the multivariable analysis based on previous studies. ${ }^{24}{ }^{25}$ Paired t-test was conducted to analyse whether there was an improvement after the EA by comparing the total points of people before and after. Associations were estimated with ORs and their respective $95 \%$ CIs. Results were considered statistically significant if the two-tailed $p$ value was $<0.05$.

Qualitative research was conducted in a total of 59 participants. The FGD was audio-recorded and transcribed verbatim in Spanish in Word and then analysed and coded using a grounded theory approach. It was translated into English for publication.

ArcGIS Online was used to create the map that illustrates the cities of residence of the participants and copyright permission was obtained from Esri, Japan.

\section{Ethical considerations}

Informed written consent was obtained from all participants. All data collected during the quantitative and qualitative parts were anonymised by code number and privacy was protected.

\section{Patient and public involvement}

Patients and the public were not involved in the design or conduct of the study.

\section{RESULTS \\ Description of the participants}

A total of 72 participants from Bolivia were recruited into the study. Participant ages ranged between 20 and 70 years old, with a mean of $45 \pm 11.9$ years old, and $55 \%$ were women. Almost $95 \%$ of the women had children. Most of the participants had secondary education (high school education; 62.5\%). More than half of the responders $(57.1 \%)$ came from areas endemic for CD. The most common department of origin was Santa Cruz $(50 \%)$, followed by Beni (34\%). Most of the participants have been living in Japan for more than 10 years (80.3\%). Mie prefecture and Kanagawa prefecture had the highest number of participants (figure 1). In addition, $37 \%$ of the participants came from other prefectures including Gunma (13.5\%), Aichi (13.5\%), Tokyo (8.4\%) and Ishikawa $(1.6 \%)$ (table 1$)$.

Characteristics of the participants related to risk factors of CD Most of the responders had heard about CD (82.8\%), although just four responders $(6 \%)$ had been tested for CD before, two of which were positive for the causative agent, Trypanosoma cruzi. More than half of the responders came from rural areas $(62.2 \%)$ and a third of the responders had lived in an adobe house (33.3\%). Most of the responders did not recognise the triatomine insect vector $(64.7 \%)$. Of the people who had seen the insect $(n=25), 11$ of them saw it at home.

In our study, $23.8 \%$ of the responders had at least one family member infected by $\mathrm{CD}$. Just two participants referred that their mothers were infected by CD. Regarding blood transmission, $10.4 \%$ of the responders received a blood transfusion in LA countries. Nearly $30 \%$ of the participants had donated blood previously (figure 2). 


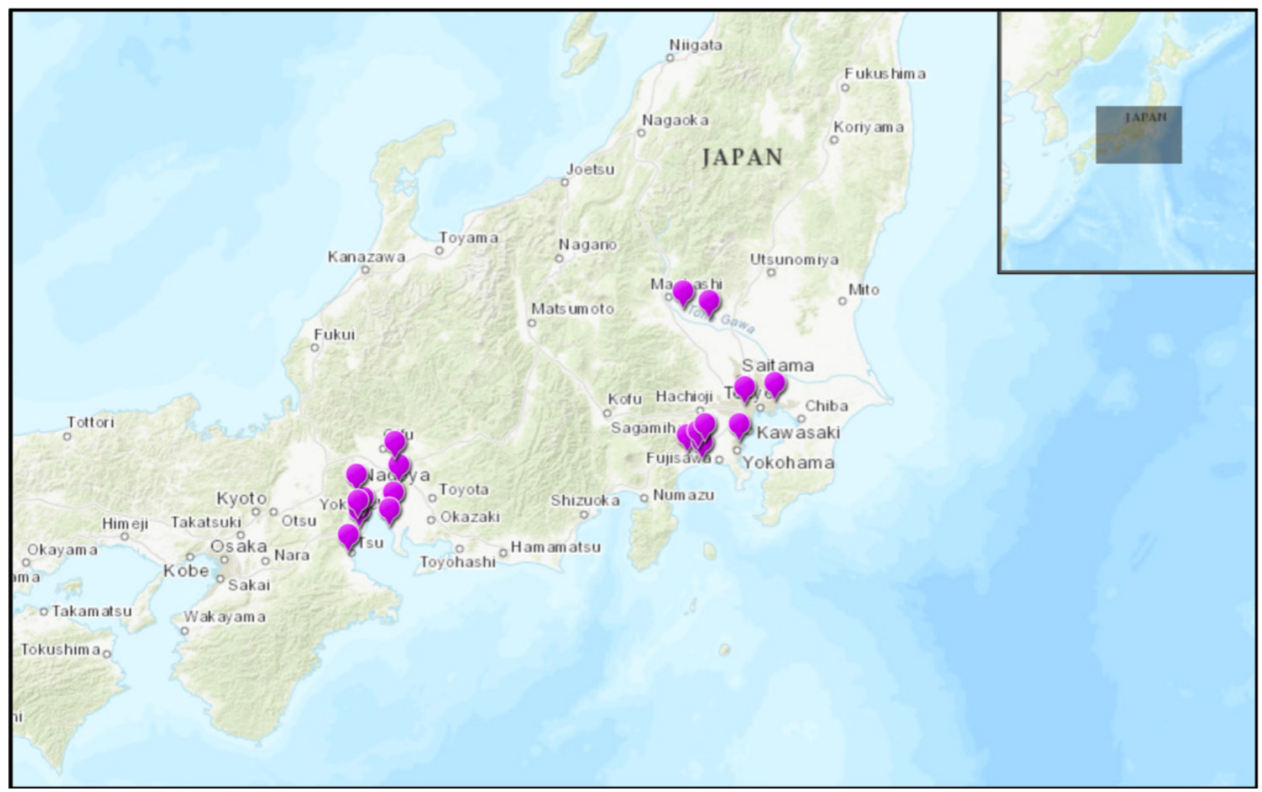

Figure 1 Cities of residence in Japan. ArcGIS online was used to illustrate the cities of residence of the participants. Copyright permission was obtained from Esri, Japan.

\section{Stigmatisation of the disease}

Most of the responders reported that they would like to be tested $(94.2 \%)$ and treated $(97 \%)$ for CD if they had the opportunity. Nearly $30 \%$ reported being worried if another person knew that they had CD (figure 2).

\section{Access in terms of coverage and satisfaction to the healthcare system}

Most of the responders reported to have health insurance in Japan $(87.8 \%)$ and, in general, they were satisfied with the care received in health centres $(95.3 \%$; figure 2$)$.

\section{Knowledge of the participants}

Baseline knowledge of the participants on CD

The total knowledge score was low with an average of 6.8 \pm 2.7 . However, the participants could identify important points of $\mathrm{CD}$, specifically, epidemiology, transmission, symptomatology and treatment. Most of the participants identified $\mathrm{CD}$ as a problem in LA countries $(85 \%)$ as well as in Japan $(70.3 \%)$. Nearly $80 \%$ of them believed that $\mathrm{CD}$ was a severe disease $(78.4 \%$; figure 2$)$.

Most responders knew that CD was endemic in LA $(27 / 61 ; 44.2 \%)$, slightly more than a second group that identified it worldwide $(23 / 61 ; 37.7 \%)$. Nearly two-thirds of the responders were familiar with vector-borne transmission $(36 / 60 ; 60 \%)$. Most of the women $(27 / 38 ; 71 \%)$ considered that the disease can affect their children if they are infected, whereas fewer $(13 / 33 ; 39.3 \%)$ understood vertical transmission as a possible route. Low knowledge about oral transmission was reported between the participants. No misidentification of person to person routes, such as hugs and kisses, was answered by the responders.

Most responders identified cardiac disease as a symptom of CD $(50 / 55 ; 90.9 \%)$. Cardiac disease alone was the most popular answer as part of the symptoms of CD with $58.1 \%$ of the answers $(32 / 55)$, followed by heart and digestive problems $(16 / 55 ; 29 \%)$.

Two-thirds of the responders considered a positive result in Chagas test to be interpreted as sickness $(37 / 57$, $64.9 \%)$, and just $21 \%(12 / 57)$ of the responders differentiated between infection and disease. Most responders $(50 / 64,78.1 \%)$ knew that there was pharmacological treatment for CD and $69.3 \%(34 / 49)$ knew that it is not useful in severe cases.

\section{Factors associated with better knowledge}

The univariable analysis showed that participants who had been living longer in Japan and had been tested for $\mathrm{CD}$ had significantly higher knowledge ( $p$ value $\leq 0.2$ ) (table 2). Our multivariable logistic regression analysis indicated that longer living in Japan was independently associated with higher knowledge. Participants who lived in Japan for more than 10 years were eight times (OR=8.40, 95\% CI 1.57 to 47.82) more likely to be knowledgeable on $\mathrm{CD}$ than those who lived for a shorter time (table 2).

\section{Knowledge improvement after EA}

Fifty-nine participants (out of 72) took part in the EA $(82 \%)$, while 3 people left the activity earlier and 10 arrived late to the venue. Among 59 participants who joined in the EA, $50(84.7 \%)$ of them performed Q1 and Q2 (figure 3).

Our paired sample t-test indicated an improvement in total knowledge of participants on CD (mean knowledge score: postactivities $9.8 \pm 2.6$ vs preactivities $6.8 \pm 2.6$, $\mathrm{p}$ value $<0.0001 ; 95 \%$ CI 2.35 to 3.89 ). Before the EA, only $20.8 \%$ of the participants $(n=15)$ exhibited a high knowledge, whereas $45.8 \%$ of the participants $(n=33)$ had high knowledge after the EA. As a result, more than $80 \%$ of the 
Table 1 Sociodemographic characteristics of the population

\begin{tabular}{|c|c|c|}
\hline & $n / N$ & $(\%)$ \\
\hline \multicolumn{3}{|l|}{ Age } \\
\hline$<40$ & $18 / 61$ & $(29.5$ \\
\hline$\geq 40$ & $43 / 61$ & $(70.4$ \\
\hline \multicolumn{3}{|l|}{ Sex } \\
\hline Male & $31 / 69$ & $(45)$ \\
\hline Female & $38 / 69$ & (55) \\
\hline Female with children & $36 / 38$ & $(94.7$ \\
\hline \multicolumn{3}{|l|}{ Education } \\
\hline Primary & $3 / 64$ & $(4.7)$ \\
\hline Secondary & $40 / 64$ & $(62.5$ \\
\hline University & $21 / 64$ & $(32.8$ \\
\hline \multicolumn{3}{|l|}{ Department of origin } \\
\hline Santa Cruz & $28 / 56$ & $(50)$ \\
\hline Beni & $19 / 56$ & (34) \\
\hline La Paz & $4 / 56$ & (7.1) \\
\hline Pando & $5 / 56$ & (8.9) \\
\hline \multicolumn{3}{|l|}{ Endemicity in place of origin } \\
\hline High & $28 / 56$ & $(50)$ \\
\hline Low & $4 / 56$ & (7.1) \\
\hline Non-endemic & $24 / 56$ & $(42.9$ \\
\hline \multicolumn{3}{|l|}{ Duration living in Japan } \\
\hline$<5$ years & $9 / 66$ & $(13.6$ \\
\hline $5-10$ years & $4 / 66$ & (6.1) \\
\hline$>10$ years & $53 / 66$ & $(80.3$ \\
\hline \multicolumn{3}{|l|}{ Resident prefectures in Japan } \\
\hline Gunma & $8 / 59$ & $(13.5$ \\
\hline Mie & $23 / 59$ & $(38.9$ \\
\hline Kanagawa & $14 / 59$ & $(23.7$ \\
\hline Aichi & $8 / 59$ & $(13.5$ \\
\hline Tokyo & $5 / 59$ & $(8.4)$ \\
\hline Ishikawa & $1 / 59$ & (1.6) \\
\hline People who have donated blood & $19 / 68$ & $(27.9$ \\
\hline
\end{tabular}

responders improved their score after the activity $(n=41$, $83.6 \%)$. Just $2 \%(\mathrm{n}=1)$ had a worse score after the EA and $14.2 \%(\mathrm{n}=7)$ did not improve. Among the group that improved, the increase in points ranged from 0.5 to 10 . Among the group that decreased their score, the average reduction in points was 2.5 .

\section{Qualitative analysis}

Baseline knowledge

The responders were familiar with the disease and had prior knowledge about the epidemiology, vector-borne transmission and cardiac problems (online supplementary table S3). Most of the participants were familiar with the word 'Chagas'. They located the disease in their countries and related it to the endemic areas. None was familiar with the flow of the disease into non-endemic areas (PC1 and 2).

Vector-borne transmission was most frequently identified as the only way of transmission. People who recognised blood transfusion as a route of transmission associated it with previous experience in which a relative had been diagnosed when going to donate blood. Other routes were not considered before they were given relevant information (PC3 and 4). The participants mostly identified cardiac problems as a disease symptom, and digestive problems were less recognised (PC5-7).

What is the first word that came to your mind when I say 'Chagas'?

The most frequent answer was related to feelings of fears, worries and memories. Fear was linked to CD for many participants. They expressed having it for lack of information, for association with disease severity, and the belief of a fast death. Other participants manifested a fear of being ill out of their country of origin (PC8 and 9).

That gives me fear (...) because you do not know, when you are not in your country. Something weird, because here is the first time you know. I would be afraid to know. (PC9: woman, group 2)

Concerns were expressed for the transmission of the disease to their relatives. Women expressed important concerns when they knew about the possibility of mother to child transmission (PC10 and 11).

Preoccupation to find out if I have the disease and my children. (PC10: woman, group 2)

The memories expressed during the FGD were related to experienced cases of $\mathrm{CD}$ and linked to feelings as fear or pain (PC12 and 13). Participants also associated with the vector and related with non-specific symptoms such as pains or heart problems (PC14 and15).

I just do not know. I wrote, "Pain", right? so I also lived in Bolivia and at the East [of the country, an endemic area of CD]. Maybe I have (...) (PC14: woman, group 3)

\section{Attitudes}

\section{Normalisation/Naturalisation}

The participants represented a situation of normalisation/naturalisation of $\mathrm{CD}$ and considered it a part of a normal life (PC16). The possibility of being sick or having some difficulties in daily life after the age of 50 was considered normal (PC17).

And in Santa Cruz that I knew, when I came, they said ah! the Chagas [tone of nonchalance]. For me it was always the bite of the vinchuca and no more. For me it was that. But now, in detail, I see the concern, which is not unnn, it's not something simple. (PC16: woman, group 1) 


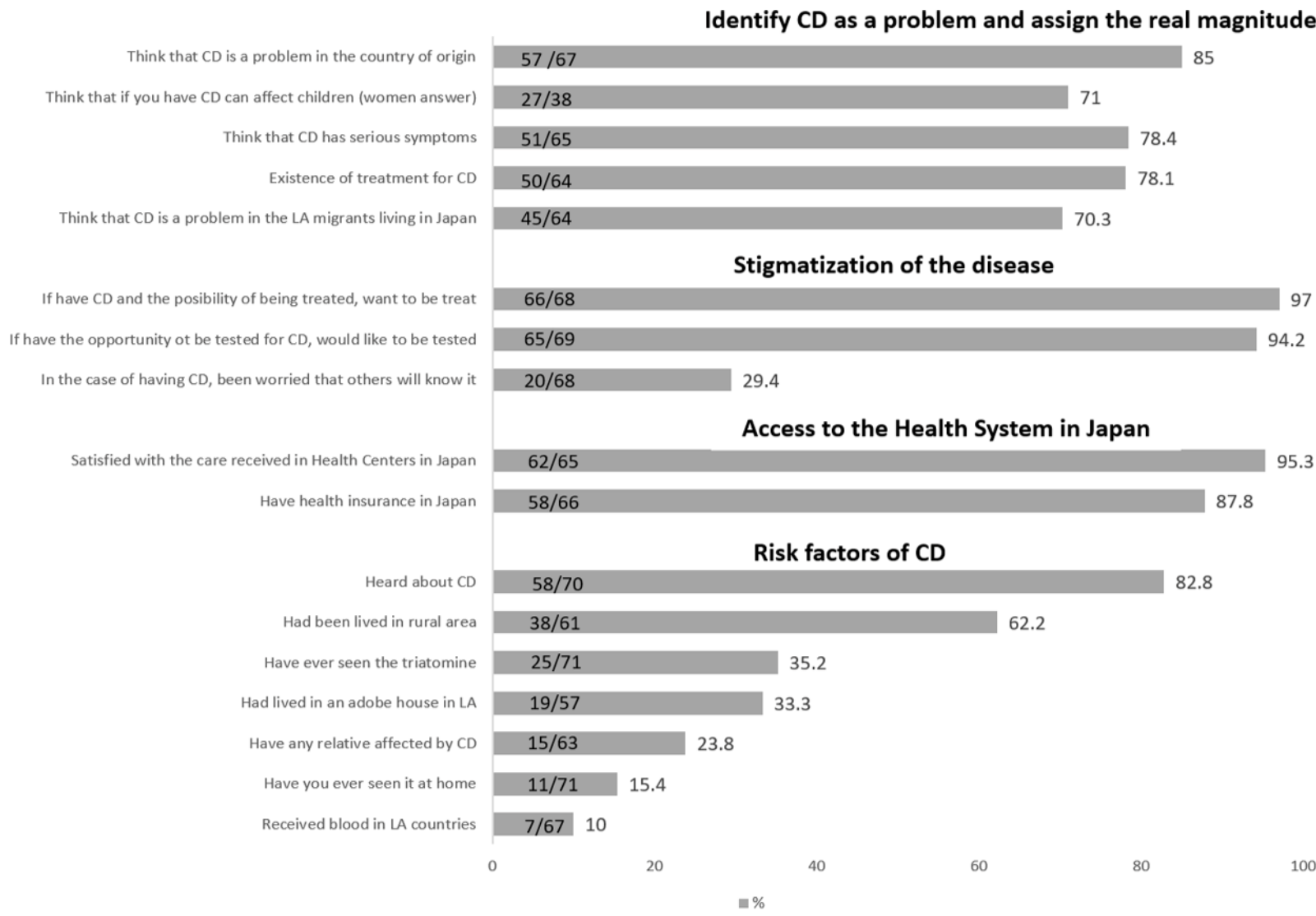

Figure 2 Answers of the participants related to risk factors of $C D$, stigmatisation of $C D$, access to the healthcare system, identification of $C D$ as a problem and assigning the magnitude of the problem. CD, Chagas disease; LA, Latin America.

\section{Stigmatisation}

Stigmatisation of the disease was not widely reported in the FGD. With the exception of two participants, they denied the existence of stigmas, after being asked if they think that stigmas exist around CD or what they thought about the fact that some communities express stigma of CD. A participant expressed a situation of stigmatisation because of misbeliefs related to the route of transmission (PC18 and 19).

\section{Resignation}

Commentaries of resignation in front of a situation where death is inescapable had been described during FGD (PC20).

\section{Barriers}

Although most participants were satisfied with the healthcare system in Japan, they identified several barriers. The language was described as a main barrier, and they reported about the accuracy of the official translations and lack of communication intimacy (PC21). The participants expressed problems in access to health services, mainly for lack of information about the healthcare system and language barrier (P22). Their prioritisation of other issues hindered them from seeking care, such as problems related to their migratory goals and their job as the main support in a foreign country (PC23-25).
Participants' proposals to overcome the observed problems Most participants considered that the spread of information in Spanish and by different media was an intervention that could improve the situation of $\mathrm{CD}$ in Japan. The internet was proposed as the most effective way to transmit information. It was suggested to distribute brochures or hold activities like the one held in this study; in venues where LA migrant population tends to gather, such as churches, Latino meetings or healthcare centres (PC26).

They also expressed the importance to distribute educational information between health sector personnel (PC27).

The participants highlighted the importance of having background information before receiving a Chagas test. They remarked on the need for accessible diagnosis, treatment and systems of care (PC28 and 29).

\section{DISCUSSION}

To our knowledge, no study has analysed the effect of EA on CD knowledge for participants in a non-endemic country. In this study, the EA included the participants as the main actors, sharing their knowledge and experiences, and this approach could have a substantial impact on knowledge improvement.

The factor that had a significant influence on acquiring a high knowledge was having lived in Japan for more 
Table 2 Univariable and multivariable analyses of factors associated with high knowledge of participants of CD

\begin{tabular}{|c|c|c|c|c|c|c|c|c|}
\hline & \multicolumn{5}{|c|}{ Univariable analysis } & \multicolumn{3}{|c|}{ Multivariable analysis } \\
\hline & $\begin{array}{l}\text { Low } \\
\text { knowledge }\end{array}$ & $\begin{array}{l}\text { High } \\
\text { knowledge }\end{array}$ & OR & Cl & $P$ value & OR & Cl & $P$ value \\
\hline \multicolumn{9}{|l|}{ Sex } \\
\hline Male & 6 & 25 & 1.11 & Reference & 0.8 & & & \\
\hline
\end{tabular}

\section{Education}

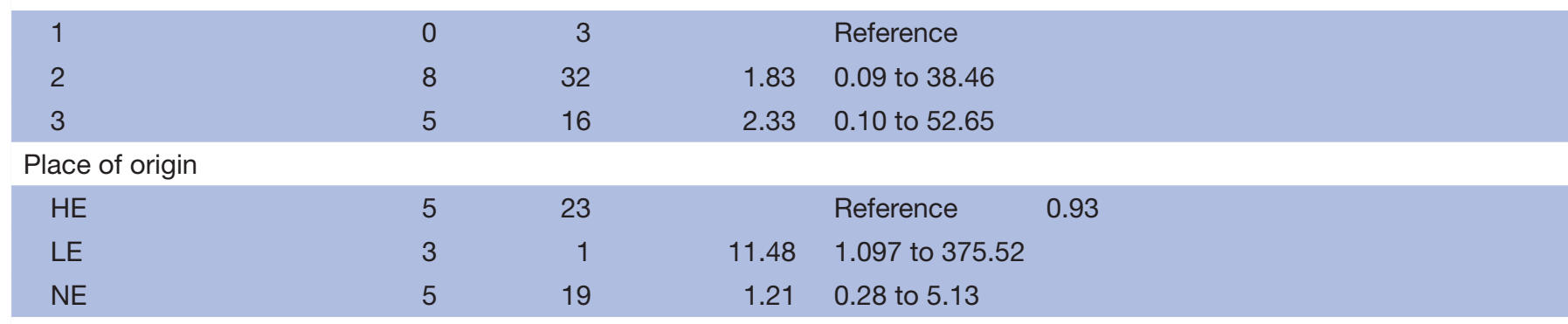

Time in Japan

\begin{tabular}{|c|c|c|c|c|c|c|c|c|c|c|}
\hline$<5$ & 4 & & 5 & & & Reference & 0.17 & & & \\
\hline $5-10$ & 1 & & 3 & & 0.47 & 0.01 to 6.07 & & & & \\
\hline \multirow[t]{2}{*}{$>10$} & 9 & & 44 & & 0.26 & 0.06 to 1.29 & & 8.40 & 1.57 to 47.82 & 0.0124 \\
\hline & Yes & No & Yes & No & & & & & & \\
\hline Lived in rural area & 10 & 3 & 28 & 20 & 0.42 & 0.10 to 1.72 & 0.33 & & & \\
\hline Lived in adobe house & 5 & 8 & 14 & 20 & 1.12 & 0.30 to 4.15 & 1 & & & \\
\hline Lived in other country & 3 & 11 & 8 & 43 & 0.68 & 0.15 to 3.01 & 0.69 & & & \\
\hline Chagas test before & 2 & 10 & 2 & 52 & 0.19 & 0.02 to 1.52 & 0.14 & 8.40 & 0.86 to 84.661 & 0.0544 \\
\hline Treatment received & 1 & 13 & 1 & 52 & 0.25 & 0.15 to 4.27 & 0.37 & & & \\
\hline Heard about CD & 13 & 1 & 45 & 11 & 0.31 & 0.04 to 2.67 & 0.43 & & & \\
\hline Recognise the triatomine & 6 & 9 & 19 & 37 & 0.77 & 0.24 to 2.49 & 0.76 & & & \\
\hline Seen the triatomine at home & 3 & 12 & 8 & 48 & 0.67 & 0.15 to 2.90 & 0.68 & & & \\
\hline Donated blood & 4 & 11 & 15 & 38 & 1.09 & 0.30 to 3.95 & 1 & & & \\
\hline History of blood transfusion & 2 & 13 & 5 & 47 & 0.69 & 0.12 to 3.98 & 0.64 & & & \\
\hline
\end{tabular}

Bold values denote only two factors with $\mathrm{p}$ value less than 0.2 (longer living in Japan and previous Chagas diagnostic test) were included in the multivariable analysis, based on previous studies. ${ }^{24} 25$

1, primary education; 2 , secondary education/high school education; 3 , university; $<5$, less than 5 years living in Japan; $>10$, more than 10 years living in Japan; 5-10, 5 to 10 years living in Japan; CD, Chagas disease; HE, highly endemic area; LE, low endemic area; NE, nonendemic area.

than 10 years. This can be explained by changes in vector control over the last decade, prior the level of infestation of Bolivian houses was higher, and thus their occupants were more familiar with CD. Today Bolivia shows greater urbanisation, ${ }^{26} 27$ and this trend may have affected awareness of a disease associated with traditional ruralism. ${ }^{613}$

Similar to the result of other studies about CD knowledge by LA migrants, the baseline knowledge of our participants was low. ${ }^{15} 28-30$ The results of our study were similar to the Blasco-Hernandez et $a l$ s study conducted in Madrid with a group of Bolivian women. ${ }^{31}$ During the quantitative and qualitative evaluations, the participants showed knowledge about aspects of $\mathrm{CD}$ such as vector habitat, epidemiology, vector-borne transmission and cardiac problems. However, knowledge of other areas was low.

Mother-to-child transmission knowledge was reported by the women of our study. As in previous studies, oral transmission was rarely considered for the participants. ${ }^{32}$ Endemic countries have focused on the reduction of vector infestation; however, there is still a lack of programmes to control other routes of transmission, and this absence can influence the awareness of the population. Knowledge about symptoms and the meaning of a positive diagnosis were not achieved, as in the study of Blasco-Hernandez et $a l^{31}$ The symptoms described for the participants in the qualitative part are represented for unspecific pain, as in previous studies. ${ }^{32}$ This may be 


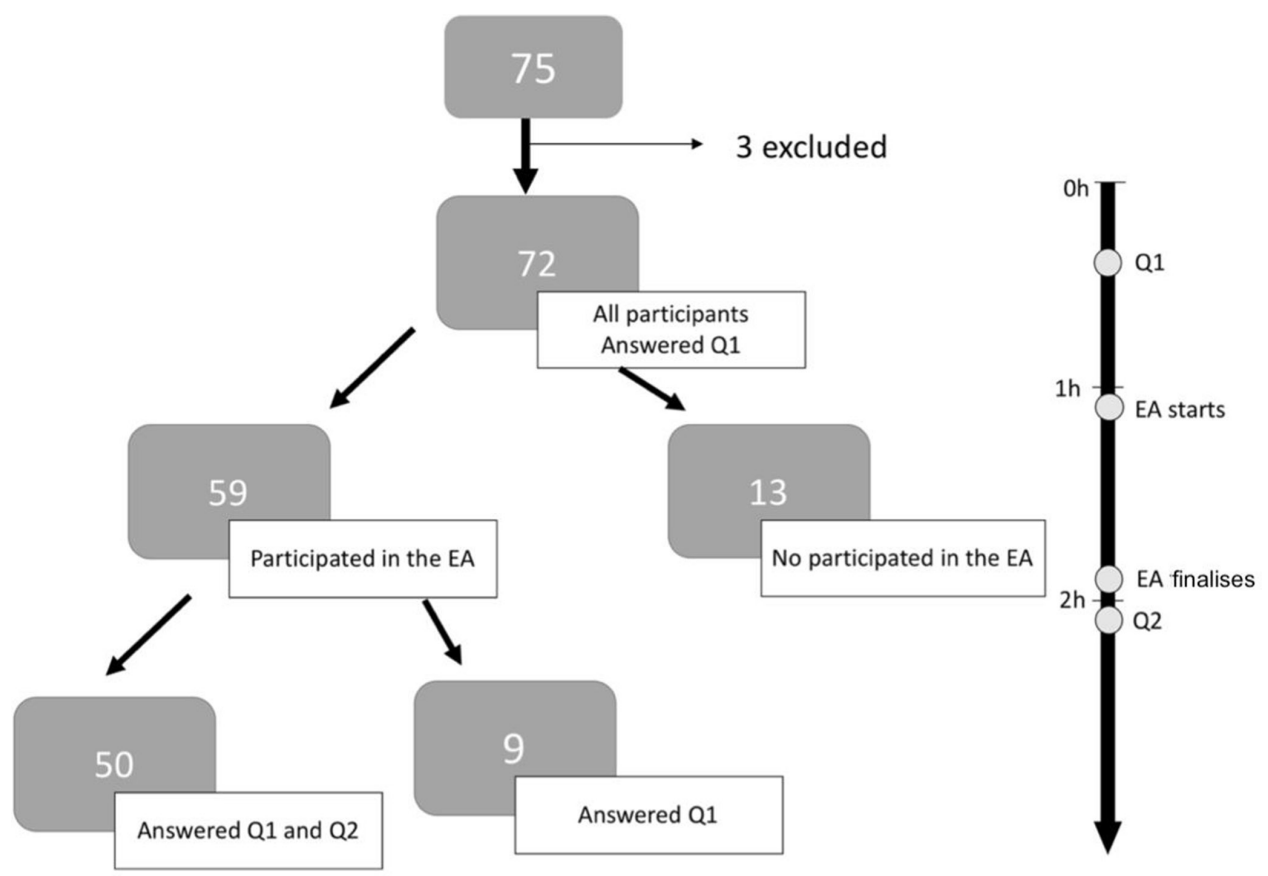

Figure 3 Flowchart of the participants included in the EA and participants who answered Q1 and Q2. EA, educational activity; Q1, questionnaire 1; Q2, questionnaire 2.

influenced by the non-specificity of the CD clinic. The course of the disease is not well known, and it is irremediably associated with high mortality. This leads to feelings of fears, worries and memories of the affected relatives. As described, this emotional burden led to the attitudes of resignation when confronted by the irremediable. The long asymptomatic period and a late diagnosis contributed to maintain this representation.

Despite prior knowledge about the disease, only $6 \%$ of the participants had been previously tested for CD. Multiple factors contribute to underdiagnosis such as lack of diagnostic tests available in the local healthcare system or minimal awareness among providers. ${ }^{33}$ However, most of the studies explained the low rate of diagnosis by the implication of sociocultural factors on the representation of the disease. The most common factors are the stigmatisation and the normalisation of the disease. ${ }^{6} 1317283134-36$ Even though most of the population at risk of $\mathrm{CD}$ are highly stigmatised, our participants showed a low level of stigmatisation. One of the possible explanations is that most of them migrated at roughly 30 years of age. They remembered cases of CD of older relatives but not proximal generation. This might make them less familiar with the ability of CD in their sociocultural context to provoke a feeling of invulnerability. Another possible explanation is that most of our participants were not diagnosed with $\mathrm{CD}$, in contrast with other studies that show a high level of stigmatisation. ${ }^{31}$ As in most of the populations analysed for CD, our participants showed a high level of normalisation/naturalisation of the disease influenced by the unspecificity of symptoms and lack of impact on daily events in the active age. In Bolivia, in the last decade, the shortened life expectancy influenced the low social relevance of $\mathrm{CD}$, although these data are changing. ${ }^{37}$

This study was conducted in Japan, where the literature on $\mathrm{CD}$ is limited to case reports and one study of prevalence in the Brazilian population. ${ }^{38}$ This is the first study to analyse the population at risk of $\mathrm{CD}$ in Japan. However, the participants represent solely Bolivians and not larger LA. Santa Cruz, a high endemic area, was the most common area of origin. This result was expected because of the migration of Japanese citizens to Bolivia after the World War II and relocation to Santa Cruz where two Japanese colonies were founded, 'Okinawa Colony' and 'San Juan of Yapacaní Colony'. We did not ask participants if they were decedents. However, the descendants of Japanese emigrants might represent an important proportion of LA migrants in Japan because of their advantage for long-term visas.

As a migrant population, several barriers were identified in the process of seeking care in Japan, including language barriers, migratory processes and difficulties to access the healthcare system. These results are similar to the barriers experienced by the LA migrant population in other non-endemic countries. ${ }^{13} 353940$

The lack of adaptability of the host healthcare system to facilitate access by the migrant population is constant. $^{1628354041}$ Our study showed that most of the participants had not known where to seek care for CD testing, and this is perhaps due to the organisation of the healthcare system in Japan, where the role of the family doctor as a coordinator is uncommon.

Studies conducted in other non-endemic countries noted that the dissemination of $\mathrm{CD}$ information was considered an important strategy for improving care 
seeking. ${ }^{3042}$ The internet was the most effective way to provide information.

An integrative educational approach is considered excellent for education, allowing visualising a complex and complete image about CD. The understanding of the implications of socialcultural factors described in the care-seeking behaviour of the migrant population is critical for designing policies, control and preventive interventions. The interventions of $\mathrm{CD}$, as the EA presented, should consider the sociocultural factors instead of a traditional specific disease-centred approach. ${ }^{13}$

The strength of our study is that most of the participants had not been tested for CD, thus providing a snapshot of the knowledge, conceptions and representations of the disease which was not strongly biased or impacted by previous contact with the healthcare system. Limitations of the study include no evaluation of knowledge over the time and no description of the impact of knowledge on care-seeking behaviour. Further, our study is focused on the Bolivian population, which might not be representative of the larger LA migrant population living in Japan. Due to a possible recall bias, the effect on knowledge over the time needs to be evaluated in future research.

Finally, the EA described here needs to be evaluated as a possible EA for health personnel in non-endemic countries. To date, no study has analysed the knowledge of Japanese doctors about CD; noting here that this knowledge is expected to be low, similar to the status of most non-endemic countries. ${ }^{43}$

\section{CONCLUSION}

In conclusion, EAs with an integrative approach are useful to increase the short-term knowledge of $\mathrm{CD}$ in the Bolivian population living in Japan. This activity brings the possibility to explore not only the knowledge but also the characteristics, experiences, opinions and needs of those at risk. This information is essential to guide the efforts to improve $\mathrm{CD}$ healthcare, by considering the people at risk as part of the improvement and development. This EA has the potential to be applied in different settings. However, the effectiveness of this activity should be evaluated in different geographical areas. We would need to assess the impact of these interventions in the long-term knowledge. Longitudinal research will bring more information on how the knowledge acquired by integral activities influences the care-seeking behaviour in $\mathrm{CD}$.

\footnotetext{
Author affiliations

${ }^{1}$ Global Health Department, School of Tropical Medicine and Global Health, Nagasaki University, Nagasaki, Japan

${ }^{2}$ Department of Immunogenetics, Institute of Tropical Medicine (NEKKEN), Leading Graduate School Program, and Graduate School of Biomedical Sciences, Nagasaki University, Nagasaki, Japan

${ }^{3}$ Faculty of Health Sciences, McMaster University, Hamilton, Ontario, Canada

${ }^{4}$ Embassy of the Plurinational State of Bolivia in Japan, Tokyo, Japan

${ }^{5} \mathrm{NPO}$ organization. MAIKEN. Motohachiojimachi, Hachioji-shi, Tokyo, Japan

${ }^{6}$ Consulate General of Brazil in Japan, Shinagawa-ku, Tokyo, Japan

${ }^{7}$ Institute of Research and Development, Duy Tan University, Da Nang, Vietnam
}

${ }^{8}$ School of Tropical Medicine and Global Health, Nagasaki University, Nagasaki, Japan

\section{Twitter Hugo Alberto Justiniano @hugonipon}

Acknowledgements The first author (IMIR) was a recipient of Otsuka Toshimi Scholarship Foundation during April 2019 to March 2020, we would like to express our gratitude to the Foundation. The authors wish to thank members of the Bolivian Embassy for their important and essential collaboration in this project. We appreciate the generous support provided by the leaders of the LA community in the different cities; namely, Mr Miguel Saucedo in Oizumi, Mrs Vania Sikujara in Suzuka, pastor Mr Jaime Teruya in Hadano and Mr Jorge Añez in Nagoya. We thank Roxana Oshiro for her great collaboration in the expansion of the activity by the media. Finally, we would like to thank the participants for sharing their experience with the community.

Contributors IMIR contributed to the conceptualisation, data curation, investigation, software and writing the original draft. IMIR, DHM, TMT, CS, NTH and $\mathrm{KH}$ contributed to formal analysis, data and interpretation. $\mathrm{KH}$ and $\mathrm{HAJ}$ contributed to the funding acquisition and resources. IMIR and KH contributed to the methodology. IMIR, KH, HAJ, SM and GI were the project administrators. The study was supervised by $\mathrm{KH}$ and SM. IMIR and NTH contributed to the visualisation. NTH, TMT and KH reviewed and edited. CS edited the English. All authors read and approved the final version.

Funding The study was supported by the Institute of Tropical Medicine (NEKKEN) and the School of Tropical Medicine and Global Health.

Map disclaimer The depiction of boundaries on the map(s) in this article does not imply the expression of any opinion whatsoever on the part of BMJ (or any member of its group) concerning the legal status of any country, territory, jurisdiction or area or of its authorities. The map(s) are provided without any warranty of any kind, either express or implied.

Competing interests None declared.

Patient and public involvement Patients and/or the public were not involved in the design, or conduct, or reporting, or dissemination plans of this research.

Patient consent for publication Not required.

Ethics approval This study received the approval of the ethics committee of the Institute of Tropical Medicine (NEKKEN) of Nagasaki University with approval number 18031188 .

Provenance and peer review Not commissioned; externally peer reviewed.

Data availability statement Data are available upon reasonable request. The full anonymous dataset can be provided on request.

Open access This is an open access article distributed in accordance with the Creative Commons Attribution Non Commercial (CC BY-NC 4.0) license, which permits others to distribute, remix, adapt, build upon this work non-commercially, and license their derivative works on different terms, provided the original work is properly cited, appropriate credit is given, any changes made indicated, and the use is non-commercial. See: http://creativecommons.org/licenses/by-nc/4.0/.

\section{ORCID iD}

Kenji Hirayama http://orcid.org/0000-0001-9467-1777

\section{REFERENCES}

1 World Health Organization. Chagas disease in Latin America: an epidemiological update based on 2010 estimates. Wkly Epidemiol Rec 2015;90:33-442.

2 Basile L, Jansá JM, Carlier Y, et al. Chagas disease in European countries: the challenge of a surveillance system. Euro Surveill 2011;16:19968-en.

3 Manne-Goehler J, Umeh CA, Montgomery SP, et al. Estimating the burden of Chagas disease in the United States. PLoS Negl Trop Dis 2016;10:e0005033-7.

4 Campo M. Una batalla por la salud de todos. El liderazgo de España en la lucha contra el Chagas. Barcelona: Instituto de Salud Global, 2017. https://www.isglobal.org/documents/10179/5808947/Informe+ El+liderazgo+de+España+en+la+lucha+contra+el+Chagas/257d4 7f1-09cd-4cee-9ae5-35e53e52bfee

5 Lee BY, Bacon KM, Bottazzi ME, et al. Global economic burden of Chagas disease: a computational simulation model. Lancet Infect Dis 2013;13:342-8. 
6 Sanmartino M. Tener Chagas en contexto urbano: concepciones de varones residentes en La region de la Plata (Argentina). Rev Biomédica 2009;20:216-27.

7 Gascon J, Bern C, Pinazo M-J. Chagas disease in Spain, the United States and other non-endemic countries. Acta Trop 2010;115:22-7.

8 e-Stat. Statistics or Japan (e-Stat), 2018. Available: https://www. e-stat.go.jp/stat-search/files?page $=1$ \&layout=datalist\&toukei= 00250012 \&tstat $=000001018034 \&$ cycle $=1$ \&year $=20170 \&$ month $=$ 12040606\&tclass1=000001060399 [Accessed 18 Jun 2019].

9 Imai K, Maeda T, Sayama Y, et al. Mother-To-Child transmission of congenital Chagas disease, Japan. Emerg Infect Dis 2014;20:146-8.

10 Imai K, Maeda T, Sayama Y, et al. Chronic Chagas disease with advanced cardiac complications in Japan: case report and literature review. Parasitol Int 2015;64:240-2.

11 Requena-Méndez A, Aldasoro E, de Lazzari E, et al. Prevalence of Chagas disease in Latin-American migrants living in Europe: a systematic review and meta-analysis. PLoS Negl Trop Dis 2015;9:e0003540:1-15.

12 Sanmartino M, Crocco L. Conocimientos sobre La enfermedad de Chagas $Y$ factores de riesgo en comunidades epidemiológicamente diferentes de Argentina. Rev Panam Salud Pública 2000;7:173-8.

13 Ventura-Garcia L, Roura M, Pell C, et al. Socio-cultural aspects of Chagas disease: a systematic review of qualitative research. PLoS Negl Trop Dis 2013;7:e2410.

14 Sanmartino M. Chagas, educación Y perspectiva CTS. Rev Iberoam CTS2010.

15 Sanchez DR, Traina MI, Hernandez S, et al. Chagas disease awareness among Latin American immigrants living in Los Angeles, California. Am J Trop Med Hyg 2014;91:915-9.

16 Navarro M, Perez-Ayala A, Guionnet A, et al. Targeted screening and health education for Chagas disease tailored to at-risk migrants in Spain, 2007 to 2010. Eurosurveillance 2011;16:1-5.

17 Sanmartino M, Amieva Nefa SC, Balsalobre A, et al. Hablamos de Chagas.. In: Aportes para (re) pensar la problemática con una mirada integral. 1st. Buenos Aires: Conicet- Consejo Nacional de Investigaciones Científicas y Técnicas, 2015. http://www. hablamosdechagas.com.ar/descargas/libros/hablamosdechagas_ aportes_para_re_pensar.pdf

18 Jackson Y, Gétaz L, Wolff $\mathrm{H}$, et al. Prevalence, clinical staging and risk for blood-borne transmission of Chagas disease among Latin American migrants in Geneva, Switzerland. PLoS Negl Trop Dis 2010;4:e592-7.

19 Grupo ¿de que hablamos cuando hablamos de Chagas? Juana Y Mateo Contra El Chagas.El Birque Animaciones.Buenos Aires (AR).Conicet Documental \& Pakapaka, 2016. Available: https:// hablamosdechagas.org.ar/juana-y-mateo-contra-el-chagas/

20 Nur AM, Azfar M, Omarulharis S, et al. Prevention Among Sub Urban Community in Sepang, Selangor'. Int J Public Health 2017;4:73-83.

21 Ahmed N, Taneepanichskul S. 'Knowledge, attitude and practice of dengue fever prevention among the people in Male, Maldives'. J Health Res 2008;22:33-7.

22 Lugo-Caballero Cl, Dzul-Rosado K, Dzul-Tut I, et al. [Knowledge of vector-borne diseases (dengue, rickettsiosis and Chagas disease) in physicians]. Gac Med Mex 2017;153:321-8.

23 Nhi DM, Huy NT, Ohyama K, et al. A proteomic approach identifies candidate early biomarkers to predict severe dengue in children. PLoS Negl Trop Dis 2016;10:e0004435-15.

24 Sherrod BA, Johnston JM, Rocque BG. Risk factors for unplanned readmission within 30 days after pediatric neurosurgery: a nationwide analysis of 9799 procedures from the American College of surgeons national surgical quality improvement program. J Neurosurg 2016;18:350-62.

25 Irie M, Nakanishi R, Yasuda M, et al. Risk factors for short-term outcomes after thoracoscopic lobectomy for lung cancer. Eur Respir J 2016;48:495-503.
26 Alonso-Vega C, Billot C, Torrico F. Achievements and challenges upon the implementation of a program for national control of congenital Chagas in Bolivia: results 2004-2009. PLoS Negl Trop Dis 2013;7:e2304

27 Moncayo A, Silveira C. Current epidemiological trends of Chagas disease in Latin America and future challenges: epidemiology, surveillance, and health policies. In: Telleria J, Tibayrenc M, eds. American trypanosomiasis Chagas disease (second edition) one hundred years of research. Academic Press, 2017: 59-88.

28 Minneman RM, Hennink MM, Nicholls A, et al. Barriers to testing and treatment for Chagas disease among Latino immigrants in Georgia. $J$ Parasitol Res 2012;2012:1-11.

29 Ramos JM, Ponce Y, Gallegos I, et al. Trypanosoma cruzi infection in Elche (Spain): comparison of the seroprevalence in immigrants from Paraguay and Bolivia. Pathog Glob Health 2012;106:102-6.

30 Navarro M, Berens-Riha N, Hohnerlein S, et al. Cross-Sectional, descriptive study of Chagas disease among citizens of Bolivian origin living in Munich, Germany. BMJ Open 2017;7:e013960:1-9.

31 Blasco-Hernández T, García-San Miguel L, Navaza B, et al. Knowledge and experiences of Chagas disease in Bolivian women living in Spain: a qualitative study. Glob Health Action 2016;9:30201:1-10.

32 Yevstigneyeva V, Camara-Mejia J, Dumonteil E. Analysis of children's perception of triatomine vectors of Chagas disease through Drawings: opportunities for targeted health education. PLoS Neg Trop Dis 2014;8:e3217.

33 Olivera MJ, Porras Villamil JF, Toquica Gahona CC, et al. Barriers to diagnosis access for Chagas disease in Colombia. $J$ Parasitol Res 2018;2018:1-14.

34 Forsyth CJ. "I Cannot Be Worried": Living with Chagas Disease in Tropical Bolivia. PLoS Negl Trop Dis 2017;11:e0005251:1-14.

35 Bayer AM, Hunter GC, Gilman RH, et al. Chagas disease, migration and community settlement patterns in Arequipa, Peru. PLoS Negl Trop Dis 2009;3:e567.

36 Aguilar SJ. Vivir con Chagas en Madrid: Una exploración antropológica de la experiencia de los pacientes bolivianos con el diagnóstico y atención médica a la enfermedad en un hospital metropolitano español[dissertation. Universidad Complutense de Madrid, 2009

37 IHME- Institute for Health Metrics and Evaluation. University of Washington (US): measuring what matters, 2018. Available: http:// www.healthdata.org/bolivia [Accessed 30 Oct 2019].

38 World Health Organization. Informal consultation on Chagas disease in the Western Pacific,Nagasaki, Japan. World Health Organization Western Pacific Region, 2011. http://iris.wpro.who.int/handle/10665. $1 / 5242$

39 Conners EE, Ordoñez TL, Cordon-Rosales C, et al. Chagas disease infection among migrants at the Mexico/Guatemala border. Am J Trop Med Hyg 2017;97:1134-40.

40 Avaria-Saavedra A. Gómez I Prat J. 07. " Si tengo Chagas ES mejor que me muera ": El desafío de incorporar Una aproximación sociocultural a la atención de personas afectadas POR La enfermedad de Chagas. Enfermedades Emergentes 2008;10:40-5.

41 Di Girolamo C, Bodini C, Marta BL, et al. Chagas disease at the crossroad of international migration and public health policies: why a national screening might not be enough. Euro Surveill 2011;16:19965-en.

42 Forsyth CJ, Hernandez S, Flores CA, et al. It's Like a Phantom Disease": Patient Perspectives on Access to Treatment for Chagas Disease in the United States. Am J Trop Med Hyg 2018;98:735-41.

43 Verani JR, Montgomery SP, Schulkin J, Jones JL, et al. Survey of obstetrician-gynecologists in the United States about Chagas disease. Am J Trop Med Hyg 2010;83:891-5. 